Bài báo khoa học

\title{
Giới thiệu bộ công cụ mô hình Wflow trong mô phỏng dòng chảy các lưu vực sông Việt Nam. Phần 1: Mô hình Wflow_sbm
}

\section{Trần Ngọc Anh ${ }^{1,2^{*}}$, Nguyễn Văn Nguyên ${ }^{3}$, Đặng Đình Đức ${ }^{1}$, Nguyễn Thanh Tùng ${ }^{1}$, Phạm Duy Huy Bình ${ }^{1}$}

1 Trung tâm Động lực học Thủy khí Môi trường, Trường Đại học Khoa học Tự nhiên, Đại học Quốc gia Hà Nội; tranngocanh@hus.edu.vn; dangduc@hus.edu.vn; nguyenthanhtung_t60@hus.edu.vn; phambinh@hus.edu.vn

2 Khoa Khí tượng Thủy văn và Hải dương học, Trường Đại học Khoa học Tự nhiên, Đại học Quốc gia Hà Nội; tranngocanh@hus.edu.vn

3 Đài Khí tượng Thủy văn khu vực Tây Bắc, Tổng cục Khí tượng Thủy văn, Bộ Tài nguyên và Môi trường; nguyentaybac@gmail.com

* Tác giả liên hệ: tranngocanh@hus.edu.vn; Tel.: +84-915051515

Ban Biên tập nhận bài: 27/11/2020; Ngày phản biện xong: 04/01/2021; Ngày đăng bài: $25 / 02 / 2021$

Tóm tắt: Trong những năm gần đây, cùng với sự phát triển của công cụ tính toán và năng lực máy tính, việc phát triển và ứng dụng các bộ mô hình thông số phân bố đang ngày càng được chú trọng và có xu hướng đáp ứng tốt hơn nhu cầu của thực tiễn về độ chi tiết theo không gian của các đầu ra mô hình. Nghiên cứu này nỗ lực giới thiệu đến với cộng đồng nghiên cứu Việt Nam bộ công cụ mô hình Wflow vốn đã được sử dụng rộng rãi trên thế giới và là một mô hình mã nguồn mở đã được tích hợp trong bộ phần mềm hỗ trợ dự báo DelftFEWS. Mô hình Wflow_sbm đã được thử nghiệm trên một số lưu vực thượng nguồn dòng chính sông Mã (đến trạm Xã Là) và sông Chu (đến hồ chứa Hủa $\mathrm{Na}$ ) cho kết quả tương đối khả quan và cho thấy khả năng ứng dụng trong tương lai ở các lưu vực sông tương tự ở Việt Nam.

Từ khóa: Mô hình Wflow; Sông Mã; Mã nguồn mở; Mô hình thông số phân bố.

\section{Mở đầu}

Hiện nay có rất nhiều các công cụ mô hình từ đơn giản đến phức tạp nỗ lực mô phỏng dòng chảy từ mưa cho các hệ thống sông ngòi. Theo cách phân chia theo sự phụ thuộc vào không gian của các thông số mô hình mà có thể phân chia các mô hình mưa dòng chảy thành các nhóm: mô hình thông số tập trung (như NAM, TANK, LTANK, SSARR, UFM,...), mô hình thông số bán phân bố (SWAT) và mô hình thông số phân bố (MARINE, TOP, B$\mathrm{TOP}, .$.$) . Các mô hình này đã và đang được ứng dụng khá đa dạng trên thế giới cũng như ở$ Việt Nam, trong đó với các tiến bộ về năng lực tính toán, khả năng cung cấp các số liệu đầu vào chi tiết theo không gian (dữ liệu địa hình, thổ nhưỡng, thảm phủ, ...) đặc biệt là với sự hỗ trợ của các công nghệ quan trắc viễn thám như số liệu mưa vệ tinh, radar, ... nhóm các mô hình thông số phân bố đã trở nên phổ biến hơn trong cả nghiên cứu và công tác dự báo nghiệp vụ. Hiện tại, Deltares (Hà Lan), cơ quan phát triển phần mềm hỗ trợ dự báo DelftFEWS (Flood Early Warning System), đã tập hợp các mô hình thủy văn phân bố dạng mã nguồn mở, được viết bằng các ngôn ngữ khác nhau (Python với các phần mở rộng PCRaster, $\mathrm{C}++$, Fortran) và liên kết các phần mềm này với nhau bằng cách sử dụng lớp $\mathrm{C} \#$ triển khai OpenMI [1] trong đó mô hình Wflow là một phần thuộc dự án Openstream. Các mô hình 
trong dự án này được chuẩn bị các giao thức để dễ dàng làm việc với các hệ điều hành cũng như các nền tảng quản lý phục vụ mô phỏng, dự báo dòng chảy, và được tích hợp như là những thành tố của bộ công cụ hỗ trợ dự báo Delft-FEWS là hệ thống đang được ứng dụng thử nghiệm tại Trung tâm Dự báo Khí tượng Thủy văn Quốc gia (Việt Nam).

Nhằm nâng cao hơn nữa khả năng ứng dụng các tùy chọn của hệ thống Delft-FEWS, nhóm nghiên cứu thuộc trường Đại học Khoa học Tự nhiên, Đại học Quốc gia Hà Nội giới thiệu bộ công cụ mô hình thủy văn trong thư viện của hệ thống và thử nghiệm khả năng ứng dụng các mô hình này trong mô phỏng dòng chảy tại các lưu vực sông ở Việt Nam. Nghiên cứu này trước hết giới thiệu về mô hình WFlow_sbm và kết quả ứng dụng cho khu vực miền núi, thiếu số liệu quan trắc bề mặt thuộc lưu vực sông Mã là lưu vực đến trạm thủy văn Xã Là trên dòng chính và dòng chảy đến hồ Hủa $\mathrm{Na}$ trên sông Chu.

\section{Giới thiệu bộ mô hình Wflow và cơ sở lý thuyết mô đun Wflow_sbm}

WFLOW là bộ mô hình thủy văn thông số phân bố mã nguồn mở của Deltares được sử dụng trong nhiều dự án để mô phỏng các quá trình mưa-dòng chảy trên quy mô lưu vực. Gần đây, chương trình WFLOW đã được phát triển thêm, giúp dễ dàng thiết lập mô hình WFLOW với dữ liệu toàn cầu ở bất cứ đâu trên thế giới. Mô hình được lập trình bằng ngôn ngữ GIS động (PCRaster) [2] với cấu trúc mở và có thể được thay đổi và phát triển bởi người sử dụng.

Mô hình thông số phân bố Wflow là bộ mô hình được thiết lập để tối đa hóa các nguồn số liệu toàn cầu mở trên thế giới do vậy có thể hỗ trợ cho các nghiên cứu ở các lưu vực thiếu số liệu. Dựa trên các dữ liệu lưới về địa hình, thổ nhưỡng, khí tượng khí hậu, mô hình Wflow có thể tính toán tất cả các chỉ số thủy văn tại bất kỳ ô lưới nào trong mô hình tại bước thời gian tính toán. Mô hình $W$ flow có thể được tích hợp và phát triển tiếp cùng với các mô hình khác thuộc Deltares như D-Hydrology, D-Flow FM và D-Water Quality (DELWAQ)... Wflow bao gồm một tập hợp các chương trình python có thể chạy trên dòng lệnh và thực hiện các mô phỏng thủy văn. Các mô hình được dựa trên khung python PCR mở rộng (lớp wf_DocateFramework) để các mô hình xây dựng bằng khung có thể được kiểm soát bằng API, liên kết đến BMI và OpenDA. Trong bộ phần mềm mô hình Wflow bao gồm nhiều mô đun có chức năng và nhiệm vụ khác nhau như: wflow_sbm, wflow_hbv, wflow_gr4, wflow_W3RA, wflow_routing, wflow_wave, wflow_floodmap, trong đó, mô hình wflow_sbm là một phần mềm độc lập trong bộ phần mềm Wflow, có thể ứng dụng để tính toán để mô phỏng các quá trình mưa-dòng chảy và đã được áp dụng ở nhiều quốc gia khác nhau.

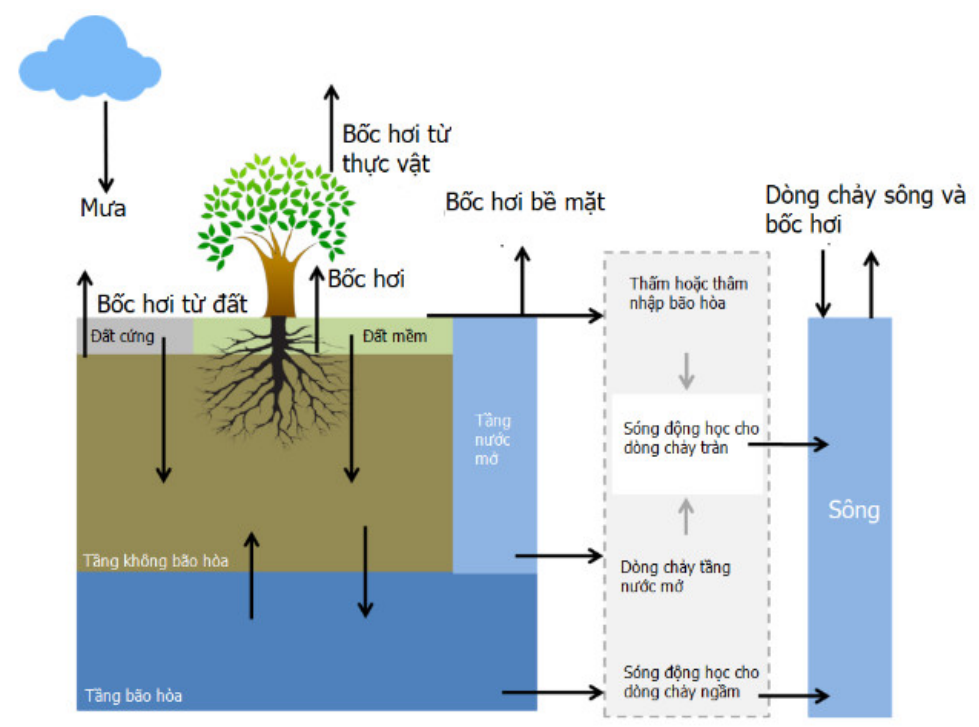

Hình 1. Các quá trình hình thành dòng chảy trong mô hình Wflow_sbm. 
Hình 1 mô tả các quá trình được mô phỏng trong mô hình wflow_sbm. Đầu tiên, mô hình sẽ xác định mạng lưới sông và điểm đo dựa trên mô hình số độ cao (DEM). Tiếp theo, bản đồ sử dụng đất và thổ nhưỡng được đưa và mô hình, và các thông số được ước tính dựa trên các đặc điểm vật lý của thổ nhưỡng và loại đất sử dụng. Lượng mưa bị tổn thất được tính toán bằng mô hình Gash $[3,4]$. Các quá trình thủy văn tạo ra dòng chảy được tính toán dựa trên mô hình TOPOG_SBM. Mô hình Wflow sử dụng lượng bốc hơi tiềm năng làm số liệu đầu vào và tính toán lượng bốc hơi thực tế dựa trên hàm lượng nước trong đất và loại thảm thực vật. Dòng chảy bề mặt được mô hình hóa bằng phương trình sóng động học. Trong trường hợp bề thổ nhưỡng đã bão hòa một phần, lượng mưa rơi trên khu vực bão hòa được tính vào dòng chảy bề mặt. Các tầng chứa nước được thể hiện bằng mô hình bể nước cơ bản, giả định độ bão hòa thay đổi theo độ sâu. Tầng nước ngầm của mô hình được mô phỏng bằng công thức Darcy. Độ sâu của đất được xác định bởi các loại sử đụng dất khác nhau và được chia tỷ lệ bằng cách sử dụng chỉ số độ ẩm địa hình. Các thông số khác nhau gắn với từng loại đất. Các thông số này bao gồm độ sâu rễ, chỉ số diện tích lá (Leaf Area Index-LAI), tỷ lệ thoát hơi nước từ tán ướt đến lượng mưa trung bình $(\mathrm{Ew} / \mathrm{R})$, độ tán xạ, trữ lượng tán tối đa, khoảng cách tán cây. Các tham số được nhập vào mô hình bằng các bảng tra cứu. Các bảng tra cứu này được mô hình sử dụng để tạo bản đồ tham số đầu vào. Các thông số được liên kết với các lớp bản đồ sử dụng đất, loại đất và các tiểu lưu vực thông qua bảng tham chiếu. Chi tiết các phương trình của mô hình bao gồm phương trình mưa ngăn chặn (1), phương trình thổ nhưỡng $(2,3,4)$ được mô tả trong nghiên cứu của $\mathrm{K}$. Hassaballah và công sự $(2018)$ [5].

$$
P^{\prime}=\frac{-\bar{R} S}{\overline{E_{w}}} \ln \left[1-\frac{\overline{E_{w}}}{\bar{R}}\left(1-p-p_{t}\right)^{-1}\right]
$$

Trong đó $\mathrm{P}$ ' là lượng nước cần để tán cây hoàn toàn bão hòa; $\bar{R}$ là lượng mưa trung bình trong một tán cây bão hòa $\left(\mathrm{mm}\right.$ ngày $\left.{ }^{-1}\right) ; \overline{E_{w}}$ là lượng bốc hơi trung bình từ tán cây ướt $(\mathrm{mm}$ ngày $\left.{ }^{-1}\right), S$ là lượng trữ tán cây $(\mathrm{mm}) ; \mathrm{p}$ là hệ số rơi qua tự do (tỷ lệ mưa rơi xuống đất mà không bị dữ lại ở tán cây) và p $\mathrm{p}_{\mathrm{t}}$ là tỷ lệ mưa chuyển thàn dòng chảy.

Trong phương trình thổ nhưỡng, thổ nhưỡng được coi là các bể nước có độ sâu khác nhau $\left(\mathrm{Z}_{\mathrm{t}}\right)$, gồm một bể chứa bão hòa $(\mathrm{S})$ và một bể chứa chưa bão hòa $(\mathrm{U})$. Trữ lượng của mỗi bể được thể hiện bằng giá trị độ sâu. Tầng $\mathrm{S}$ ở trên cùng tính đến độ sâu $\mathrm{Z}_{\mathrm{i}}$ được tính bằng công thức:

$$
\mathrm{S}=\left(\mathrm{Z}_{\mathrm{t}}-\mathrm{Z}_{\mathrm{i}}\right)\left(\Theta_{\mathrm{s}}-\Theta_{\mathrm{r}}\right)
$$

Trong đó $\Theta_{\mathrm{s}}$ và $\Theta_{\mathrm{r}}$ là hàm lượng nước bão hòa và dư trong đất tương ứng.

Tầng chưa bão hòa được chia thành 2 bể là bể chứa $\left(U_{\mathrm{s}}\right)$ và bể thiếu hụt $\left(\mathrm{U}_{\mathrm{d}}\right)$ :

$$
\begin{gathered}
U_{d}=\left(\Theta_{s}-\Theta_{r}\right) Z_{i}-U \\
U_{s}=U-U_{d}
\end{gathered}
$$

\section{3. Úng dụng thử mô hình WFlow_sbm ở tiểu lưu vực sông Mã đến trạm Xã Là và tiểu lưu vực sông Chu đến hồ chứa Hủa $\mathrm{Na}$}

\subsection{Giới thiệu về các lưu vục nghiên cưu}

Lưu vực dòng chính sông Mã đến trạm thủy văn Xã Là, có diện tích lưu vực khoảng 6.430 km², bao gồm một phần của các huyện Mường Ảng, Tuần Giáo, Điện Biên Đông thuộc tỉnh Điện Biên, một phần của các huyện Thuận Châu, Mai Sơn, và $100 \%$ diện tích của huyện Sông Mã, huyện Sốp Cộp thuộc tỉnh Sơn La (Hình 2). Địa hình ở đây chủ yếu là các dãy núi cao, độ dốc lớn, khá phức tạp, bị chia cắt mạnh bởi các dãy núi cao chạy theo hướng Tây Bắc-Đông Nam xen kẽ với các thung lũng và hệ thống sông, suối. Điểm cao nhất là đỉnh núi Pu Huổi Luông (xã Nà Sáy, huyện Tuần Giáo, tỉnh Điện Biên) cao 2.179 m, điểm thấp nhất tại mặt cắt cửa ra trạm thủy văn Xã Là có độ cao $275 \mathrm{~m}$ so với mực nước biển. Trong lưu vực và lân cận có 2 trạm khí tượng và 9 điểm đo mưa, chủ yếu có số liệu quan trắc liên tục, đồng bộ từ năm 1981 . 


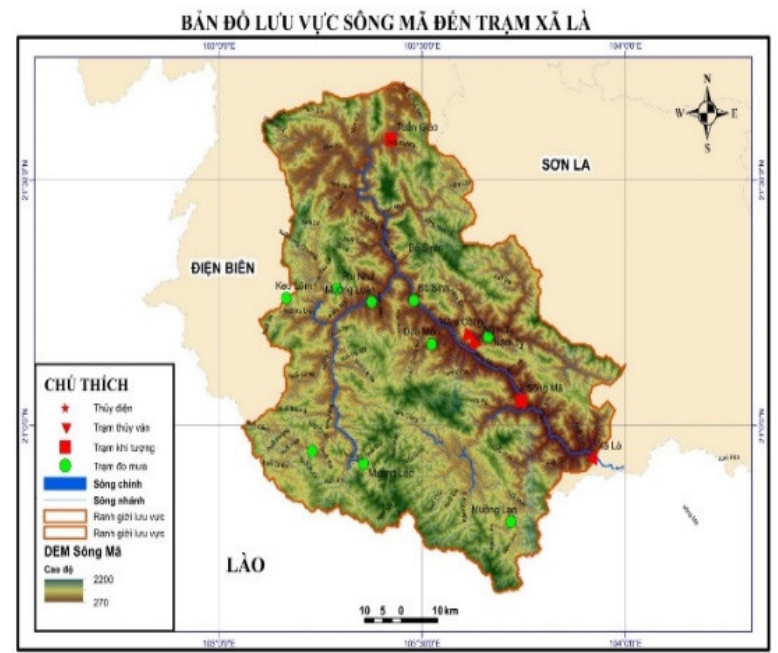

Hình 2. Bản đồ địa hình lưu vực sông Mã đến trạm Xã Là.

Lưu vực sông Chu tính đến hồ Hủa $\mathrm{Na}$, có diện tích lưu vực khoảng 5.345 km², phần lớn diện tích thuộc địa phận của Lào (chiếm $90 \%$ diện tích) và một phần của huyện Quế Phong thuộc tỉnh Nghệ An (Hình 3). Địa hình ở đây chủ yếu là các dãy núi cao, độ dốc lớn, khá phức tạp, bị chia cắt mạnh bởi các dãy núi cao chạy theo hướng Tây Bắc-Đông Nam xen kẽ với các thung lũng và hệ thống sông, suối. Điểm cao nhất là đỉnh núi Phu Nam (Huổi Phăn, Lào) cao độ $+2050 \mathrm{~m}$, điểm thấp nhất tại khu vực mặt cắt cửa ra (tuyến công trình đập Hủa $\mathrm{Na})$ có cao độ tự nhiên khoảng $+152 \mathrm{~m}$ so với mực nước biển. Trong lưu vực và lân cận có 1 trạm khí tượng và 6 điểm đo mưa, chủ yếu có số liệu quan trắc liên tục, đồng bộ từ năm 1981 .

BÄN ĐO LULL VUุC SÔNG MÃ ĐÉN HO HỦANA

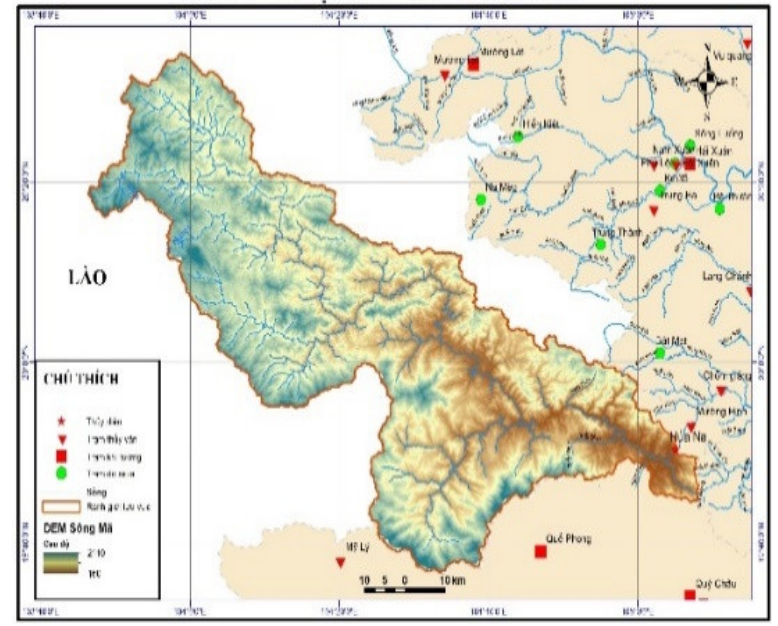

Hình 3. Bản đồ địa hình lưu vực sông Chu đến hồ Hủa Na.

\subsection{Chuẩn bị dũ liệu đầu vào}

Nhằm phục vụ thiết lập mô hình và xác định các bộ thông số, các loại dữ liệu, số liệu đã thu thập trên các lưu vực nghiên cứu bao gồm: số liệu quan trắc các yếu tố mưa ngày của 11 trạm mưa: Điện Biên, Mường Chà, Pha Đin, Thuận Châu, Sông Mã, Xã Là, Mỹ Lý, Quế Phong, Quỳ Châu, Cửa Đạt, Mường Lát, số liệu lưu lượng trung bình ngày tại trạm Xã Là năm 2015, 2017, số liệu lưu lượng đến hồ Hủa Na (4obs/ngày) các năm: 2016,2017,2018; bản đồ địa hình tỷ lệ 1/50.000 (phần lưu vực sông Mã thuộc địa phận Việt Nam), bản đổ thổ nhưỡng (huyện Sông Mã, huyện Sốp Cộp). Phần lưu vực thuộc Lào sử dụng nguồn địa hình 
SRTM (30x30m), thảm phủ thực vật từ MCD12Q1.006 MODIS, thổ nhưỡng từ FAO (Digital Soil Map of the World, năm 2007).

BẢX ĐÔ THỤC PHÜ LUUU VỰC SÔNG MÃ ĐÉN HÓ HŬANA

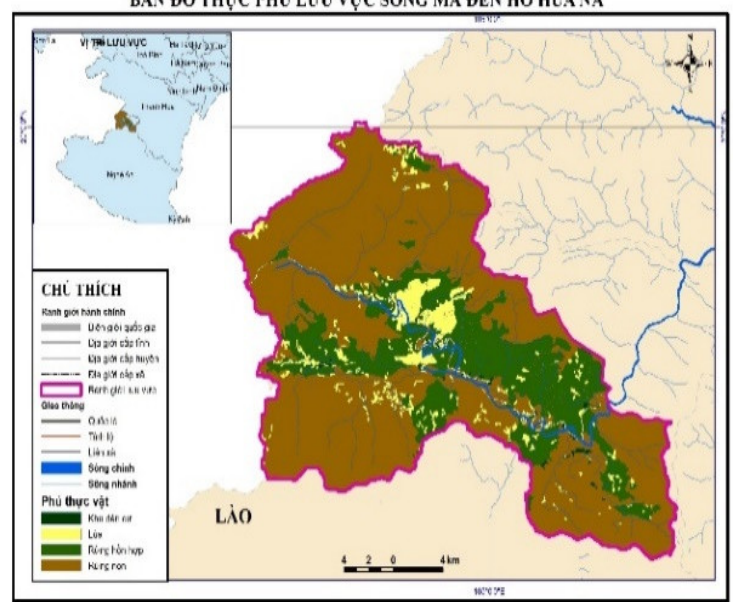

Hình 4. Bản đồ lớp phủ thực vật lưu vực sông Mã đến trạm Xã Là.

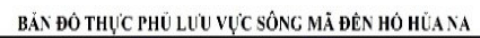

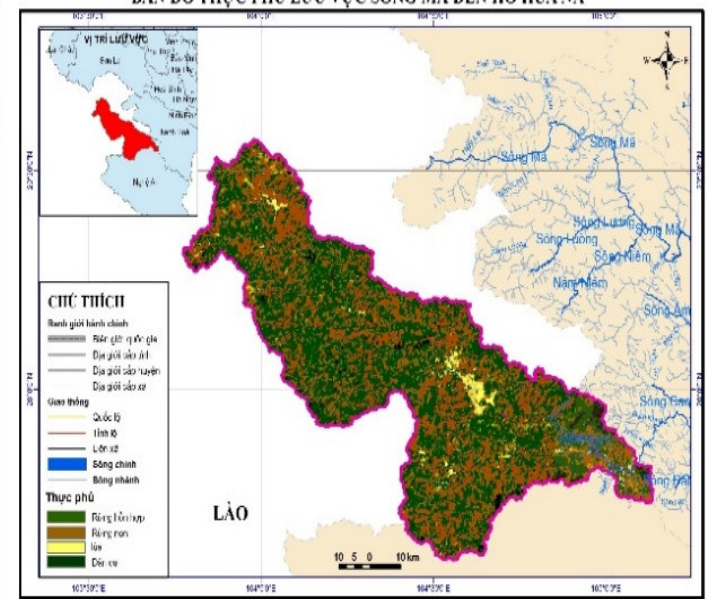

Hình 5. Bản đồ lớp phủ thực vật lưu vực sông Chu đến hồ Hủa Na.

\subsection{Thư nghiệm mô hình Wflow_sbm}

Nhằm mục đích thống nhất cho các nghiên cứu ở giai đoạn tiếp theo, mô hình Wflow_sbm được thiết lập bao trùm toàn bộ diện tích lưu vực sông Mã với 43.520.204 phần tử. Nhằm đánh giá khả năng mô phỏng của mô hình WFLOW, nghiên cứu tiến hành hiệu chỉnh và kiểm định mô hình với giai đoạn gần đây 2015-2018 (đây là giai đoạn thông tin về số liệu, tài liệu thảm phủ, thổ nhưỡng, mưa, dòng chảy khá đầy đủ và đồng nhất). Kết quả mô phỏng giai đoạn hiệu chỉnh (2015-2017) cho thấy: số liệu dòng chảy mô phỏng và thực đo khá tương đồng, cụ thể tại Xã Là: năm 2015 chỉ số Nash-Sutcliffe đạt 0,61, chỉ số PBIAS là 18,55, năm 2016 chỉ số Nash-Sutcliffe đạt 0,51 , chỉ số PBIAS là 34,5, năm 2017 chỉ số Nash-Sutcliffe là 0,66, chỉ số PBIAS là 18,57 (Hình 6-8, Bảng 1). Tại Hủa Na: năm 2016 chỉ số Nash-Sutcliffe đạt 0,74 , chỉ số PBIAS là 12,38, năm 2017 chỉ số Nash-Sutcliffe là 0,80, chỉ số PBIAS là -5,24 (Hình 10-11, Bảng 1). Bộ thông số thu được trong giai đoạn hiệu chỉnh được sử dụng để mô phỏng cho năm 2018 (kiểm định). Kết quả cho thấy, tại trạm Xã Là chỉ số Nash-Sutcliffe là 0,72 , chỉ số PBIAS là 17,4 (Hình 9, Bảng 1), tại Hủa Na chỉ số Nash-Sutcliffe là 0,70 , chỉ số PBIAS là -1,41 (Hình 12, Bảng 1). Kết quả cho thấy mô hình được xem là tốt khi giá trị chỉ số Nash-Sutcliffe và chỉ số PBIAS đều đạt mức chính xác tốt đạt yêu cầu về chất lượng mô phỏng. 


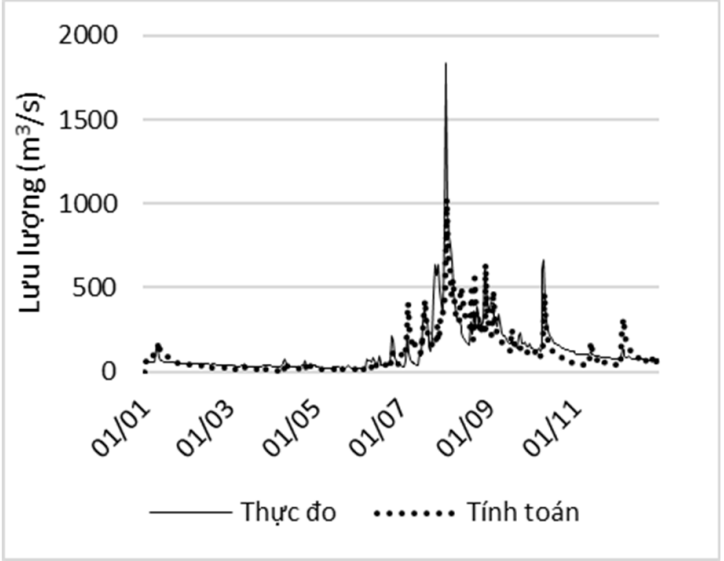

Hình 6. Kết quả mô phỏng với giá trị thực đo lưu lượng đến trạm Xã Là giai đoạn hiệu chỉnh năm 2015.

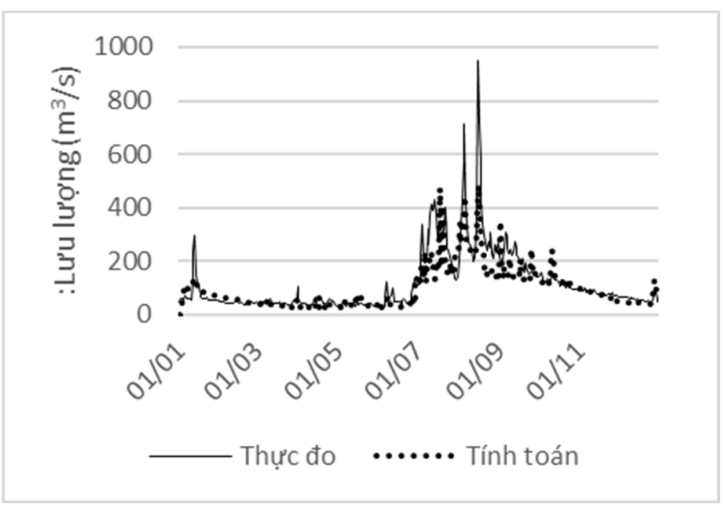

Hình 8. Kết quả mô phỏng với giá trị thực đo lưu lượng đến trạm Xã Là giai đoạn hiệu chỉnh năm 2017.

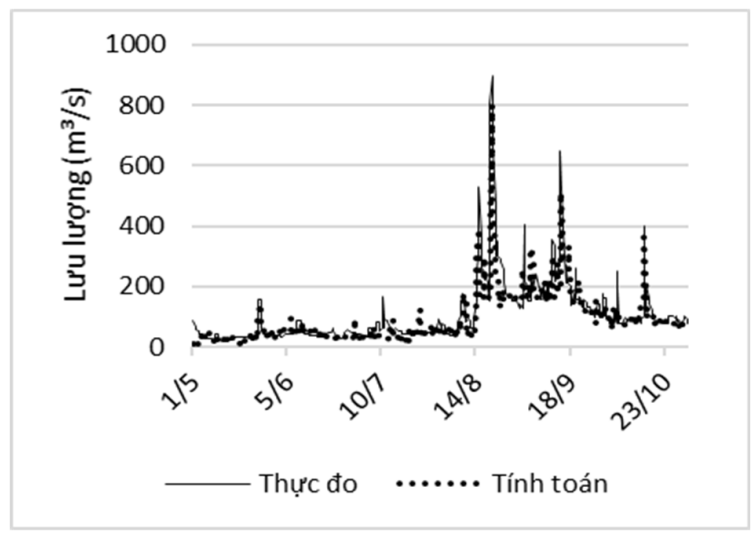

Hình 10. Kết quả mô phỏng với giá trị thực đo lưu lượng đến hồ Hủa Na giai đoạn hiệu chỉnh năm 2016.

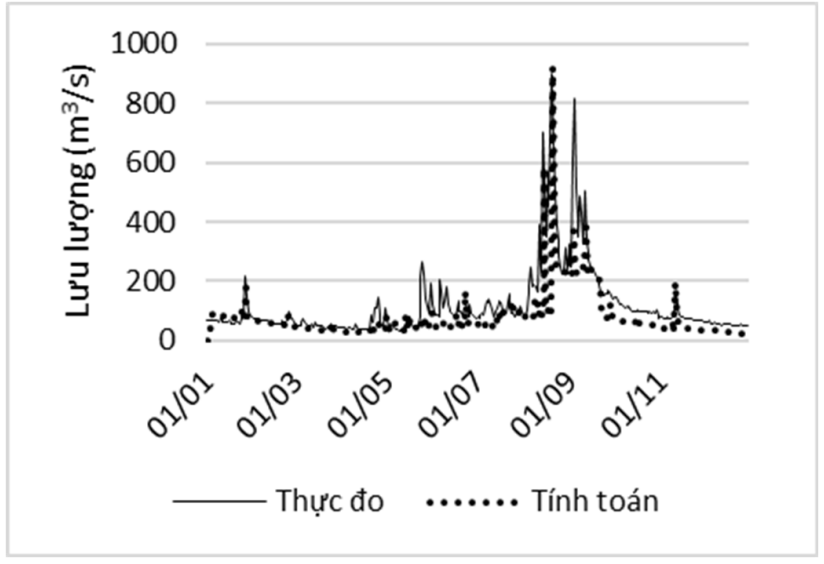

Hình 7. Kết quả mô phỏng với giá trị thực đo lưu lượng đến trạm Xã Là giai đoạn hiệu chỉnh năm 2016.

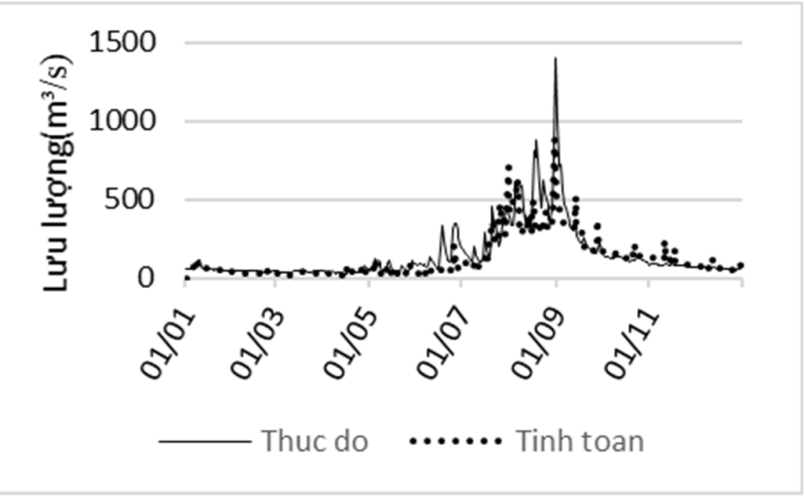

Hình 9. Kết quả mô phỏng với giá trị thực đo lưu lượng đến Xã Là giai đoạn kiểm định năm 2018.

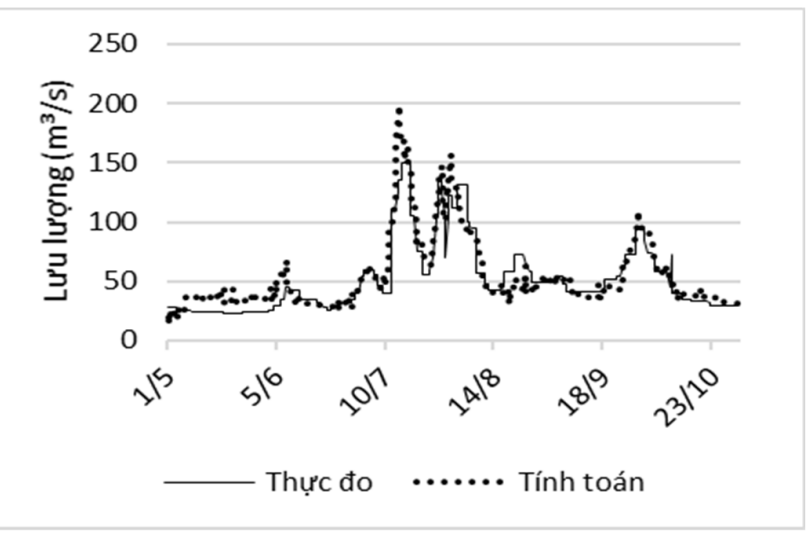

Hình 11. Kết quả mô phỏng với giá trị thực đo lưu lượng đến hồ Hủa Na giai đoạn hiệu chỉnh năm 2017. 


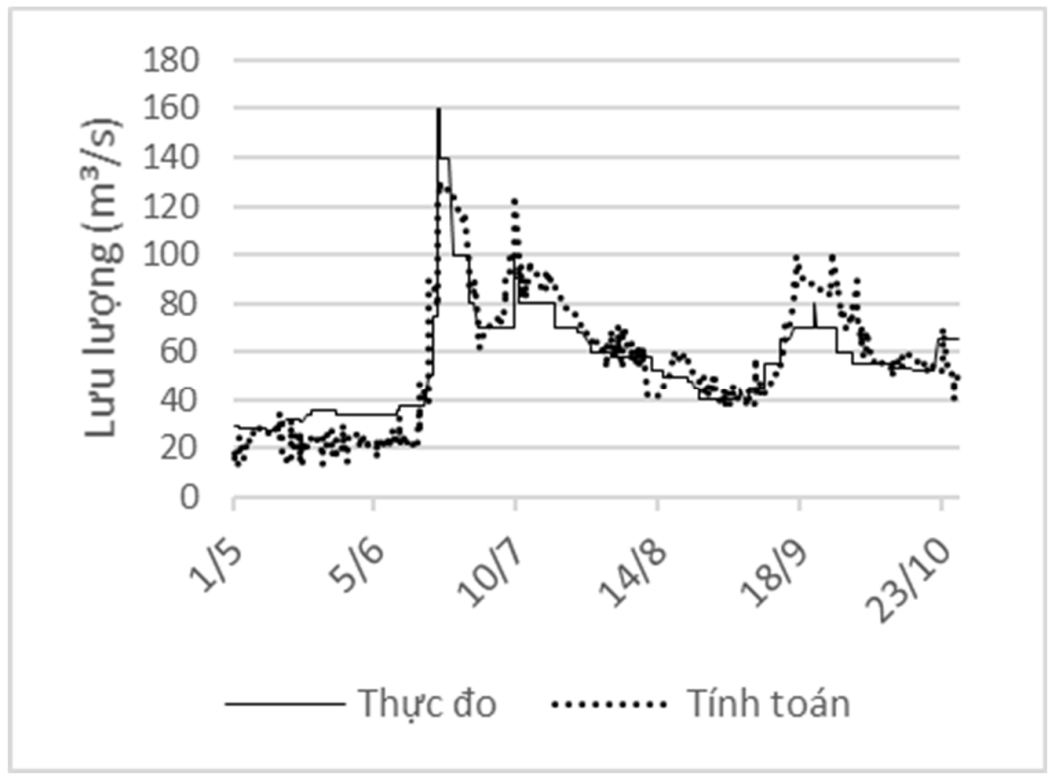

Hình 12. Kết quả mô phỏng với giá trị thực đo lưu lượng đến hồ Hủa Na giai đoạn kiểm định năm 2018.

Bảng 1. Kết quả hiệu chỉnh và kiểm định mô hình WFLOW.

\begin{tabular}{cccccl}
\hline \multirow{2}{*}{ Năm } & \multicolumn{2}{c}{ NASH } & \multicolumn{2}{c}{ PBIAS } & \multirow{2}{*}{ Ghi chú } \\
\cline { 2 - 5 } & Xã Là & Hủa Na & Xã Là & Hủa Na & \\
\hline 2015 & 0,61 & & 18,55 & & Hiệu chỉnh \\
2016 & 0,51 & 0,74 & 34,5 & 12,38 & Hiệu chỉnh \\
2017 & 0,66 & 0,80 & 18,57 & $-5,24$ & Hiệu chỉnh \\
2018 & 0,72 & 0,70 & 17,4 & $-1,41$ & Kiểm định \\
\hline
\end{tabular}

Như vậy, bộ thông số tìm được (Bảng 2) có độ tin cậy để có thể sử dụng trong công tác mô phỏng phục hồi số liệu dòng chảy trạm thủy văn Xã Là từ số liệu các trạm mưa trên lưu vực và lân cận hoặc có thể làm cơ sở để xây dựng các phương án dự báo dòng chảy ngày hoặc phục vụ công tác đánh giá theo các kịch bản như BĐKH hay tác động của các công trình.

Bảng 2. Bộ thông số mô hình WFLOW.

\begin{tabular}{|c|c|c|c|}
\hline Tên thông số & Mô tả & $\begin{array}{l}\text { Gía trị cho lưu } \\
\text { vụcc trạm Xã Là }\end{array}$ & $\begin{array}{c}\text { Gía trị cho lưu vực } \\
\text { đến hồ Hủa Na }\end{array}$ \\
\hline $\mathrm{N}$ & Hệ số maning của đất & $0,03-0,07$ & $0,035-0,06$ \\
\hline N_River & Hệ số maning trong sông & $0,025-0,035$ & $0,032-0,045$ \\
\hline MaxLeakage & Lượng nước rò rỉ ra khỏi đất & 1 & 1.5 \\
\hline RunoffGeneratingGWPerc & $\begin{array}{l}\text { Phân số độ sâu của đất góp } \\
\text { phần tạo ra dòng chảy phụ }\end{array}$ & 0,2 & 0,5 \\
\hline thetaR.tbl & Hàm lượng nước dư & $0,01-0,05$ & $0,03-0,06$ \\
\hline KsatVer & Độ dẫn bão hoà & $5-25$ & $5-25$ \\
\hline
\end{tabular}




\subsection{Nhận xét}

Kết quả bước đầu trên lưu vực sông Mã tại các trạm thượng nguồn (Xã Là, Hủa $\mathrm{Na}$ ) cho thấy đây là một mô hình khá hiệu quả trong việc mô phỏng dòng chảy. Mô hình này có một số ưu điểm nổi bật: là mô hình mã nguồn mở, cho phép người dùng cải tiến mô hình; tốc độ tính toán nhanh, ổn định trên window và linux; công tác chuẩn bị số liệu đầu vào đơn giản khi kết hợp với các công cụ GIS thông dụng như ArcGIS, QGIS; tương thích cao với hệ thống hỗ trợ dự báo FEWS đang được triển khai dự báo nghiệp vụ tại Trung tâm Dự báo Khí tượng Thủy văn Quốc gia... Bên cạnh đó, mô hình còn tồn tại một số nhược điểm chưa có công cụ hỗ trợ trong việc dò tìm thông số tối ưu cho mô hình, mô phỏng chưa tốt với các khu vực có địa hình bằng phẳng.

\section{Kết luận và kiến nghị}

Nghiên cứu đã xây dựng bộ mô hình thủy văn phân bố WFLOW_sbm, áp dụng tính toán dòng chảy cho lưu vực sông Mã. Mô hình đã được hiệu chỉnh và kiểm định với chuỗi số liệu lưu lượng trung bình ngày tại trạm thủy văn Xã Là và đến hồ Hủa Na. Các kết quả đánh giá về sai số đáp ứng được yêu cầu cho phép mô hình có thể sử dụng để mô phỏng đánh giá diễn biến dòng chảy ngày, tháng trên lưu vực. Trong thời gian tiếp theo, nhóm tác giả sẽ tiếp tục nghiên cứu ứng dụng bộ công cụ này để mô phỏng dòng chảy lũ trên lưu vực.

Đóng góp của tác giả: Xây dựng ý tưởng nghiên cứu và phân công nhiệm vụ triển khai: T.N.Anh; Lựa chọn phương pháp nghiên cứu: T.N.A., Đ.Đ.Đ., N.T.T., P.D.H.B.; Hiệu chỉnh, kiểm định mô hình và chạy các kịch bản: N.V.N., N.T.T., Đ.Đ.Đ., P.D.H.B.; Viết bản thảo bài báo: T.N.A., P.D.H.B., Đ.Đ.Đ.; Chỉnh sửa bài báo: N.V.N., N.T.T., P.D.H.B.

Lò̀i cảm ơn: Nghiên cứu này được thực hiện tại Trung tâm Động lực học Thủy khí Môi trường, Trường Đại học Khoa học Tự nhiên, Đại học Quốc gia Hà Nội. Bên cạnh đó, tập thể tác giả trân trọng cảm ơn sự giúp đỡ của các đài trạm trên mạng lưới lưu vực sông Mã trong quá trình khảo sát và thực hiện nghiên cứu này.

Lò̀i cam đoan: Tập thể tác giả cam đoan bài báo này là công trình nghiên cứu của tập thể tác giả, chưa được công bố ở đâu, không được sao chép từ những nghiên cứu trước đây; không có sự tranh chấp lợi ích trong nhóm tác giả.

\section{Tài liệu tham khảo}

1. Schellekens, J.; Becker, B.; Donchyts, G.; Goorden, N.; Hoogewoud, J.C.; Patzke, S.; Schwanenberg, D. OpenStreams: Open Source Components as Building Blocks for Integrated Hydrological Models. EGU General Assembly Conference Abstracts 2012, 3953.

2. Deursen, W.P.A. Geographic Information Systems and Dynamic Models. Netherlands Geogr. Stud. 1995, pp. 190.

3. Gash, J.H.C. An analytical model of rainfall interception by forests. Q.J.R. Meteorol. Soc. 1979, 105, 43-55.

4. Gash, J.H.C.; Lloyd, C.R.; Lachaud, G. Estimating sparse forest rainfall interception with an analytical model. J. Hydrol. 1995, 170, 79-86.

5. Hassaballah, K.; Mohamed, Y.; Uhlenbrook, S.; Biro, K. Analysis of streamflow response to land use and land cover changes using satellite data and hydrological modelling: Case study of Dinder and Rahad tributaries of the Blue Nile (EthiopiaSudan). Hydrol. Earth Syst. Sci. 2017, 21, 5217-5242. https://doi.org/10.5194/hess21-5217-2017. 


\title{
Introduction of WFLOW model toolkit for flow simulation in Vietnamese river basins. Part 1: Wflow_sbm model
}

\author{
Tran Ngoc Anh ${ }^{1,2^{*}}$, Nguyen Van Nguyen ${ }^{3}$, Dang Dinh Duc ${ }^{1}$, Nguyen Thanh Tung1, \\ Pham Duy Huy Binh ${ }^{4}$ \\ ${ }^{1}$ Center for Environmental Fluid Dynamics, VNU University of Science, Vietnam \\ National University, Hanoi, Vietnam; tranngocanh@hus.edu.vn; dangduc@hus.edu.vn; \\ nguyenthanhtung_t60@hus.edu.vn; phambinh@hus.edu.vn \\ 2 Faculty of Hydrology, Meteorology and Oceanography, VNU University of Science, \\ Vietnam National University, Hanoi, Vietnam; tranngocanh@hus.edu.vn \\ ${ }^{3}$ Northwest Regional Hydrometeorology Centre, Viet Nam Meteorological and \\ Hydrological Administration, Ministry of Natural Resources and Environment; \\ nguyentaybac@gmail.com
}

\begin{abstract}
In recent years, along with the development of computational tools and computing capabilities, the development and application of distributed (parameter) model sets have been increasingly paid attention. This research attempts to introduce to the Vietnamese researcher community the $\mathrm{W}$-flow modeling toolkit which has been widely used around the world and is an open-source model that has been integrated in the forecasting support software (Delft-FEWS). The Wflow_sbm model has been tested on a number of basins upstream of the Ma River (upto Xa La station) and Chu River (upto Hua $\mathrm{Na}$ reservoir) with the good results hence shows the applicability in the similar river basins in Vietnam.
\end{abstract}

Keywords: WFlow model; Ma River; Open source; Distributed model. 